\title{
Análisis de contenido de fotografías científicas de la naturaleza: propuesta de una plantilla
}

\author{
Anne-Vinciane DOUCET \\ Universidad de Granada. Facultad de Ciencias Económicas y Empresariales. Biblioteca \\ avdoucet@ugr.es
}

Recibido: Noviembre 2013

Aceptado: Enero 2014

\begin{abstract}
Resumen: Se propone una plantilla para el análisis de contenido de fotografías científicas de la naturaleza. En primer lugar, se define la fotografía científica, su público y los condicionantes de su análisis. En segundo lugar, se destaca la importancia del texto acompañando las fotografías para su recuperación. En tercer lugar, se describen los modelos de Lasswell, de Panofsky y Shatford y la semiología para el análisis de las fotografías, antes de detallar el método seguido para el análisis de contenido. Por último, se presenta la funcionalidad de la plantilla para la redacción de un resumen y asignación de descriptores. Se concluye destacando su interés para encontrar las pistas informativas transmitidas por las fotografías y la necesaria colaboración entre fotógrafo y documentalista.
\end{abstract}

Palabras clave: fotografías científicas; análisis de contenido; semiología; modelo de Lasswell; modelo de Panofsky

\section{Analysis of the content of nature scientific photographs: proposal of a pattern}

\begin{abstract}
This article proposes a pattern to analyse the content of scientific photographs. In a first part, it defines scientific photographs, its public and its analysis. In a second part, it deals with the importance of the text which encloses the photographs to be retrieved. In a third part, it describes the Lasswell model, the Panofsky and Shatford models, and the semiology. The method followed to analyse photographs is then detailed. In a fourth part, it stresses how useful is the pattern statistically to write an abstract and to assign keywords, before it concludes about the importance to detect the informative clues transmitted by the photographer and the necessary collaboration between photographer and information professional.
\end{abstract}

Keywords: scientific photographs; content analysis; semiology; Lasswell model; Panofsky model

\section{INTRODUCCIÓN}

Hoy en día, la sociedad es altamente visual, las imágenes ya no son sólo una forma de información complementaria (ACRL/IRIG, 2011). Las representaciones visuales penetran en nuestras vidas, sobre todo en el mundo de las ciencias, donde 
se usan imágenes tanto en conferencias como en artículos (Pozzer-Ardenghi et al., 2005). Además, la fotografía está por todos sitios: exposiciones, galerías, museos, noticias... (Rittau, 2007). Las nuevas tecnologías permiten a cada uno crear y compartir información visual (ACRL, 2011). Por un lado, se comparten fotografías en redes sociales (Lee, et al. 2010; Enser, 2008) y, por otro lado, se etiquetan. Como señala Enser (2008), el etiquetado social ha traído una nueva dimensión para la representación del contenido semántico de los materiales visuales y esto se refleja en productos como Flickr $^{1}$ o Youtube ${ }^{2}$.

En definitiva, cuando hablamos de imágenes, hablamos también de texto, bien como etiquetas o bien como textos que acompañan la fotografía. La recuperación de imágenes se realiza o bien a través de conceptos semánticos (concept-based image retrieval) o bien con elementos relativos a las texturas, colores y formas (content-based image retrieval) (Enser, 2008). Ménard (2009) distingue estos tipos de recuperación entre nivel bajo (características físicas) y nivel alto (indización realizada por un indizador humano o automático), y subraya que la vía más rápida para recuperar imágenes es la indización con una descripción textual, sea con un vocabulario controlado o con vocabulario natural.

Nos centraremos en la asignación de conceptos semánticos y en la redacción de un resumen de la fotografía. Ahora, nos preguntamos: ¿cómo conseguir un resumen de la imagen? Esto se obtiene mediante el análisis de la imagen, con distintos métodos y modelos de comunicación. Esta propuesta se basa en un estudio sobre fotografías científicas de la naturaleza del banco de imágenes "Indigo base", del IRD realizado para una tesis doctoral (Doucet, 2008a) y es parte de los resultados de dicha tesis.

\section{OBJETIVOS E HIPOTESIS}

Partimos de la base de que a partir de un análisis detallado de la fotografía, se pueden encontrar pistas informativas y redactar un resumen. Nuestro objetivo general es proponer una plantilla para el análisis de las fotografías, que permita destacar los elementos imprescindibles para su posterior resumen y detectar pistas informativas, utilizando los elementos textuales ya existentes. Así se facilita la recopilación de datos por parte de los documentalistas y su posterior organización en una base de datos para imágenes.

\footnotetext{
${ }^{1}$ http://www.flickr.com/

${ }^{2} \mathrm{http}: / / \mathrm{www}$. youtube.com/?gl=ES\&hl=es

${ }^{3} \mathrm{http}: / / w w w . i n d i g o . i r d . f r / i n d e x . p g i$
} 
Los objetivos específicos para alcanzar el objetivo general son los siguientes:

1. Definir un método de análisis de contenido de la fotografía basándonos en los niveles de Panofsky, en los elementos de Lasswell y en la connotación según Barthes

2. Analizar los elementos textuales (leyendas y palabras clave) según los niveles de Panofsky y el modelo de Lasswell, para detectar el tipo de información que da (análisis complementario al análisis de contenido de las fotografías)

3. Comprobar la funcionalidad de la plantilla

La hipótesis de trabajo es que la representación documental de las fotografías científicas se consigue mediante un análisis pormenorizado de los elementos visuales y textuales ya presentes, combinando varios modelos.

\section{LA FOTOGRAFÍA CIENTIFICA, SU PÚBLICO Y LOS CONDICIONANTES DE SU ANALISIS}

\subsection{LA FOTOGRAFÍA CIENTÍFICA}

Un científico utiliza la imagen científica como una herramienta de interpretación y de reconstrucción del mundo real (Cacaly, 2005). Es su mirada sobre el objeto que hace que sea científica, ya que es él quien elige lo que quiere mostrar o no mostrar (Lissalde, 2001). La imagen científica suele estar acompañada de un texto, que completa la información de la imagen, como comentamos en la introducción.

Lissalde (2001) destaca dos tipos de imágenes científicas. El primero que se encuentra en la prensa general y en la científica y el segundo tipo que tiene que ver con el arte. Señalamos que se puede también clasificar la fotografía como de laboratorio o de la naturaleza.

\subsection{EL PÚBLICO}

Una imagen puede tener una gran amplitud de aplicaciones y de público (Chung, et al., 2011). Los públicos pueden ser historiadores, profesores y estudiantes, ilustradores, arquitectos, diseñadores, coleccionistas, bibliotecarios o productores de televisión (Cahuzac, 2000; Ménard, 2012). El fin con el que se utilizan las imágenes es diferente según el público. Por ejemplo, se pueden usar imágenes para integrarlas en un producto secundario, como puede ser el caso tanto de editores como de publicistas, diseñadores, productores de televisión...(Rasmussen, 1997). Por consiguiente, conocer el público de un banco 
de imágenes es importante para responder a sus necesidades y adaptarse a las formulaciones de búsqueda, que serán diferentes para cada tipo de público (Cahuzac, 2000). En cuanto al público de las fotografías científicas, consideramos que puede ser tanto un público de científicos que utilizan las fotografias con fines científicos o un público que las reutilizan con fines de divulgación.

Centrándonos en la creación de un banco de imágenes, Stephenson (1999) destaca que se debe tener en cuenta quién es el destinatario, qué es lo que se está construyendo, cuál es la finalidad y qué funcionalidades necesitan los usuarios. Ilustremos este hecho citando a Melot (1994), que destaca que son diferentes las necesidades de los museos de las de las agencias de prensa o de los centros de documentación iconográficos. Estos centros difieren en sus descripciones, ya que unos catalogan con exhaustividad objetos en número limitado (museos) con un objetivo de investigación y conservación, mientras que otros deben seguir reglas expeditivas para grabar miles de documentos diarios, con un objetivo comercial y muchas veces efímero.

El análisis de las fotografías se enfoca de forma distinta según el público, ya que la indización se basa en sus necesidades y en el uso de que se hará de la fotografía una vez recuperada. Como explica Massignon (2002), dos personas indizan una misma fotografía de forma diferente, por eso, los resultados pueden variar. Por eso, es importante saber a qué público nos dirigimos. Queremos subrayar que, además, el usuario formula su pregunta según sus conocimientos, basándose en los niveles de Panofky (véase el punto 4-c). Si entiende sólo el nivel pre-iconográfico, no preguntará con términos iconográficos, aunque las significaciones iconográficas de las imágenes le pueden satisfacer (Shatford Layne, 1986). Esto demuestra la complejidad del proceso de la búsqueda de imágenes y la importancia de conocer al público para adaptarse a sus necesidades y reflejarlas en el tratamiento documental.

Esta investigación se centra en un público que reutiliza las fotografías con fines de divulgación (para publicaciones o exposiciones) y que necesita un resumen de la fotografía y de sus posibles significaciones.

\subsection{CONDICIONANTES DEL ANÁLISIS}

Analizar una fotografía conlleva diferentes condicionantes. El primero es el propio analista, puesto que al analizar la fotografía, se juntan sus interpretaciones, su cultura, su psicología, su formación, sus conocimientos, su memoria... Rittau (2007) subraya que la fotografía parece dialogar con la memoria visual. Los análisis más inconscientes (nuestro ojo y cerebro organizan la información icónica dándonos sensaciones visuales) se interpenetran y se enriquecen los unos con los otros. Melot (2005) destaca que una imagen no es ni mono ni polisémica en sí, sólo se deja ver. Somos nosotros los que creamos uno o varios sentidos al verla. Por eso, y como hemos comentado brevemente anteriormente, el análisis de una 
fotografía realizado por dos personas con formación distinta, será diferente: por ejemplo, un geógrafo analizará el paisaje de una fotografía y un radiólogo mirará el barrido de una imagen por un sistema susceptible de restituir esta imagen sobre un tubo catódico (Hudrisier, 1982). Es más, se puede llegar a describir de forma idéntica las imágenes (condición necesaria para su intercambio), pero no ocurre lo mismo para la asignación de palabras clave. No se consigue crear unanimidad en su asignación, puesto que depende de los elementos inconscientes descritos anteriormente (Melot, 1994). De hecho, para Hudrisier (1982), si una imagen tiene un fin cultural, se debe pensar en todas las asociaciones míticas, totémicas, artísticas, representaciones del inconsciente colectivo, religiosas... para poder encontrar la imagen pertinente.

Otro condicionante es el propio documento. La calidad de reproducción es importante para la lectura de la imagen, que funciona según la analogía (Melot, 2005). Por ejemplo, podemos leer un poema de García Lorca sobre una mala fotocopia y no afectará a su calidad literaria. En cambio, no es lo mismo ver la Gioconda en el Louvre que en una postal o una fotocopia en blanco y negro.

Ahora que hemos presentado la fotografía científica, vamos a ver los elementos textuales que se relacionan con ella.

\section{ELEMENTOS TEXTUALES RELACIONADOS CON LA FOTOGRAFÍA}

Queremos empezar destacando la variedad de elementos textuales existentes en relación con las fotografías. Según un estudio realizado sobre la normalización de la descripción de 30 bancos de imágenes (Doucet, 2008b), estos, en las fichas que detallan cada imagen, suelen ofrecer una variedad de elementos (tanto en su número como en su terminología). Los más empleados suelen ser la descripción, la autoría, el título y las palabras clave, ya que permiten la identificación y la descripción de la imagen. En cuanto a la terminología, hay que tener en cuenta que una descripción de una fotografía suele ofrecer varios nombres como descripción, leyenda o evento o, como subraya Péquignot (2006), también se puede llamar comentario, ilustración, explicación o interpretación. Pinto et al. (2002) hablan además de representación documental, refiriéndose al resumen y a los descriptores relacionados con las fotografías. Además de estos elementos de texto, cada banco de imágenes (sea comercial, institucional o de fotógrafos profesionales) ofrece datos específicos del uso de su propio mecanismo, como por ejemplo datos técnicos de la cámara, el donante de la fotografía, comentarios de los usuarios registrados, el nombre del fichero de la imagen, el soporte original, el tamaño numérico, la latitud y la longitud del lugar de la toma fotográfica... (Doucet, 2008a).

Aparte de la consideración lexicológica del texto que acompaña la fotografía, es importante destacar su función como ayuda comprensiva. Por ejemplo, en una conferencia donde se utilizan fotografías, hace falta recursos semiológicos que 
ayuden a entender los elementos importantes de ésta (Pozzer-Ardengui, 2005). Si consideramos la fotografía como objeto cultural, sólo una persona con ciertos conocimientos culturales puede denotarla, ya que una fotografía representa objetos o situaciones desconocidas por el analista (Bléry, 1981). Por eso, debe llevar una descripción con informaciones precisas, tales como la fecha, el país, si existen monumentos o personas, y una explicación de la acción, de forma que se pueda situar y entender lo que estamos viendo en la fotografía. Se recomienda además cierta estructura en la redacción de la leyenda para facilitar la lectura y la búsqueda en texto completo (Kattnig, 2005).

Además del texto, se suelen añadir palabras clave o descriptores. Los tipos de descriptores suelen ser onomásticos (quién), toponímicos (dónde), temáticos (qué), cronológicos (cuándo) y connotativos. Estos últimos enriquecen el proceso permitiendo recuperar por otros puntos de acceso (Robledano Arillo, 2000).

Ahora que se ha destacado la importancia de los elementos textuales, vamos a centrarnos en los métodos a seguir para analizar el contenido de las fotografías.

\section{MODELOS Y MÉTOdOS PARA EL ANÁLISIS DE CONTENIDO DE LAS FOTOGRAFÍAS}

Los diferentes modelos existentes para analizar las fotografías son los siguientes: modelo de Lasswell, métodos de análisis de imágenes que, como destaca Kattnig (2005), son de dos categorías: los elaborados alrededor de la teoría del signo (la semiología (Roland Barthes) y la semiótica (Charles Sanders Peirce)) y, los del área de historia del arte, elaborados por Edwin Panofsky y Ernst Hansa Gombricht. El objetivo es conocerlos para poder combinarlos en una plantilla para analizar las fotografias.

\subsection{EL MODELO DE LASSWELL}

Este método describe el contenido de una fotografía mediante las $5 \mathrm{Ws}$ : Who says What in Which channel to Whom with What effect? que corresponden a lo siguiente (Valle Gastaminza (1993), Moreiro (2001) y Hernández Pérez (1992)):

- Quién: identifica la persona representada de forma precisa (nombre, edad, sexo, profesión o función), los animales y las infraestructuras.

- Qué: describe la acción realizada y no las acciones invisibles.

- Canal: trata del soporte utilizado para transmitir la señal al receptor.

- A quién: se centra en el estudio del público, afecta al "qué".

- El efecto: incide en el proceso de recepción de los mensajes. 
Este análisis se completa con criterios espacio-temporales:

- Dónde: sitúa geográficamente la toma fotográfica de la forma más precisa posible (continente, país, ciudad, nombre de un río o de un sitio) (Kattnig et al., 1989).

- Cuándo: identifica la fecha o el periodo determinado: época histórica, estación solar, fecha exacta, momento del día...

\subsection{LA SEMIOLOGÍA}

La semiología es el análisis de la producción de un significado (Hudrisier, 1982). Se entiende como la descripción rigurosa de un contenido manifestado, bien por lenguas diferentes de las lenguas naturales, o bien por significantes que constituyen los objetos del mundo o los comportamientos humanos (Porcher, 1976). Por eso, se puede utilizar para analizar el contenido de las imágenes.

La metodología de Barthes para el análisis semiológico se basa en la estructura del signo de Saussure: un significante vinculado a un significado (Joly, 1994). Se trata de apoyarse en los significados para encontrar los significantes, y así los signos que componen la imagen. El método de Joly (1994) es inverso: hacer corresponder los diferentes significantes del mensaje visual con los significados de uso. Así, la síntesis de los significados puede ser una versión del mensaje vehiculado por la fotografía.

Vamos a recordar lo que son los signos lingüísticos e icónicos.

\subsubsection{EL SIGNO LINGÜÍSTICO Y EL SIGNO ICÓNICO}

De Saussure (1973) lo define como lo que une un concepto (o significado) con una imagen acústica (significante) y lo representa con la siguiente figura:

Figura 1. Signo lingüístico (De Saussure, 1973)
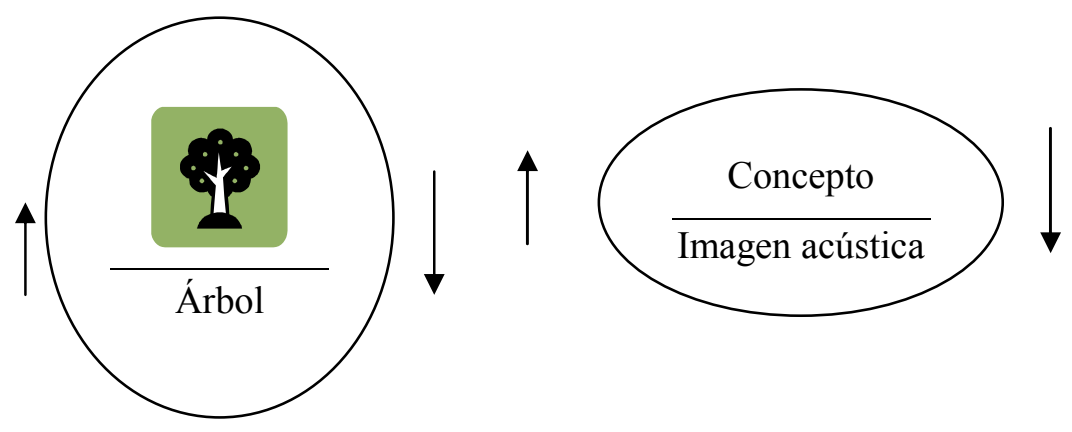
Saussure llama al significado "concepto" (Barthes, 1964), lo que representa la significación o significaciones del significante. En semiología, objetos, imágenes o gestos son significantes y reenvían a algo que se puede decir sólo a través de ellos mismos, con la diferencia de que el significado semiológico puede depender de los signos del lenguaje.

Otro concepto importante es el valor. Si se corta una hoja de papel en tres partes A, B y C, cada parte tiene, por un lado, un valor en comparación con las demás partes $\mathrm{y}$, por otro lado, cada una tiene dos caras que han sido cortadas a la vez (A-A', B-B', C-C'), que es su significación (De Saussure, 1973). Por consiguiente, la significación se produce a partir de la correlación de significante y significado y a partir de un corte simultaneo de dos masas amorfas. Por ejemplo, el valor conceptual en inglés de mutton es diferente al de sheep, por el hecho de que sheep tiene una segunda palabra que es mutton. El valor formal tiene que ver con los cambios ortográficos de la palabra del singular al plural o por el cambio de letras, como es el caso de "nieve" y "nieto". Se diferencian formalmente por la "v" y por la "t."

Para Gubern (1988: 119) "el signo icónico posee una concreción significante (plus de información) del que carece el signo verbal, dotado de mayor abstracción." El signo visual se parece al signo lingüístico: un significante vinculado a un significado. El significante es lo que vemos, como el dibujo de una palmera en un papel. El significado es el concepto de palmera.

\subsection{MODELO DE PANOSFKY Y DE SHATFORD}

Según Panofsky (1998), existen tres niveles de significación: el nivel preiconográfico, el nivel iconográfico y el nivel iconológico. El primer nivel de significación se basa en la identificación de las formas puras (representaciones de objetos, personas, plantas...). El significado puede ser fáctico (identifica las formas visibles) o expresivo (produce algún sentimiento a partir de la identificación de estos objetos y acciones y funciona por empatía). El segundo nivel (nivel iconográfico) se basa en el reconocimiento de los motivos presentes en la imagen. Por último, el tercer nivel (nivel iconológico) es el descubrimiento y la interpretación de estos valores "simbólicos", que se perciben tanto por "métodos compositivos" como por significación iconográfica (Panofsky, 1972).

Shatford Layne (1986) utiliza los niveles de Panosky llamándolos genérico (pre-iconográfico), específico (iconográfico) y abstracto (iconológico), y le añade facetas: quién, qué, cuándo y dónde para la indización de las imágenes. Además, en el primer nivel, diferencia entre significación objetiva y significación subjetiva.

Este modelo, llamado Panofsky/Shatford, se ha vuelto un modelo generalizado para la clasificación de las descripciones de las imágenes, siendo utilizado por varios investigadores (Hollink et al., 2004 ; Jaimes et al., 2000). 


\subsection{MODELOS DE ANÁLISIS DE CONTENIDO}

Resumimos las aportaciones de varios autores sobre el análisis de contenido de las imágenes. Se compone de un análisis morfológico que divide las características técnicas, formales y de composición de la imagen (Chaumier, 1988; Bléry, 1976). Estos elementos crean significación e interpretación (Madrid Díaz, 1999), puesto que la forma de fotografiar influye en su interpretación. Según Berger (2000), la fuerza de la imagen reside en la composición, ya que ella hace que se desplace el ojo y conduce a modos de lecturas distintos (Vettraino-Soulard, 1983). Como dice Joly (1994), tiene que asegurar que los espectadores centren su atención en los elementos principales y no secundarios. Una de las principales reglas de la composición es la regla de los tercios, que divide la imagen vertical y horizontalmente en tres partes iguales. Los puntos de intersección son los puntos fuertes que resaltan el centro de interés (Fernández y Martínez, 2001).

El análisis de contenido se compone de los análisis denotativo y connotativo. Coincidimos con Porcher (1976) quien define la denotación en la fotografía como la descripción del carácter analógico de todas las fotografías en relación con la realidad fotográfica. Permite identificar el contenido y señalar los personajes, lugares y acciones. Como destaca Shatford Layne (1986) para analizar el tema de una imagen es necesario intentar determinar el significado transmitido por ésta, y las relaciones entre este significado y las palabras empleadas para describirla.

La connotación es lo que la fotografía hace pensar al lector (Valle Gastaminza, 1993). Se divide en objetiva y subjetiva (Kattnig et al., 1989). La connotación objetiva se basa en la memoria colectiva y es función del entorno sociocultural: son determinados gestos, actitudes, símbolos o colores que cambian de significado según cada país (Moreiro, 2001). La connotación subjetiva corresponde a lo que cada uno interpreta.

Barthes (2002) define un sistema de significación compuesto por un plano de expresión (E) y un plano de contenido (C), cuya significación se obtiene a partir de la relación (R) de los dos planos: E R C. Supongamos que existen dos sistemas y que el primer sistema se vuelve el plano de expresión o significante del segundo.
2. $\mathrm{E}$
$\mathrm{R}$
$\mathrm{C}$
1. ER C

La denotación es el primer sistema, mientras que el segundo constituye la connotación. Se dice de un sistema que es connotado cuando el plano de expresión está constituido por un sistema de significación (Barthes, 1990).

Se puede representar mediante este esquema:

Figura 2. La connotación según Barthes (Barthes, 1964)

\begin{tabular}{|l|l|l|}
\hline \multicolumn{2}{|l|}{ Significante } & Significado \\
\hline Significante & Significado & \\
\end{tabular}


Dicho de otra forma, la denotación se forma mediante un significante que se une con un significado. Esta unión crea un nuevo significante connotativo que, a su vez, tiene su propio significado (Barthes, 1964).

En cuanto a la connotación de las imágenes científicas, queremos destacar que éstas surgen como resultado del conjunto de elecciones que, en base a su intención, lleva a cabo el autor en el momento de su creación (elección del objeto, habilidad técnica, selección de una imagen entre otras para una exposición, elecciones estéticas, elecciones didácticas...) (Sicard, 1993). Estas elecciones traspasan el objetivo de la cámara y muestran datos reveladores sobre el autorcreador. Así, podemos afirmar que una imagen científica sí posee connotaciones a nivel morfológico.

\subsection{MÉTODO PROPUESTO}

En este apartado, presentamos la inclusión de los diferentes modelos explicados anteriormente para analizar las fotografias científicas, tal cómo se refiere el objetivo específico 1, descrito en el apartado 1.

Consideramos que toda fotografía científica existe para transmitir una información (ya sea en una exposición, en manuales, en artículos científicos...), por consiguiente, tiene una significación. El análisis de la significación de las fotografías depende de la intención del fotógrafo, que no conocemos. Por eso, debemos preguntarnos a la hora de analizar una fotografía: ¿Qué es lo que quiere decir la fotografía?, ¿sobre qué elementos quiere llamar la atención? Estas preguntas se realizan de cara a intuir las posibles pistas informativas. En nuestro trabajo, proponemos un método que se basa en cuatro fases para describir las imágenes y encontrar las posibles pistas informativas de forma que permitan guiar en la comprensión de la significación de la fotografía. Para las tres primeras fases (análisis morfológico, análisis denotativo y análisis connotativo) nos hemos basado en Bléry (1976), Wertel-Fournier (1999), Gerverau (1997); y para la cuarta fase, nos hemos basado en los valores de los signos. A nivel formal, los signos se diferencian por su posición en la composición, por su tamaño en comparación con los demás elementos visibles y por su situación en los planos de la fotografía. En cuanto al valor conceptual, son elementos diferentes, por ejemplo, un glaciar no es una nube. Consideramos que una fotografía transmite un mensaje formado por la agrupación de los signos destacados, por lo que pensamos que la detección de su valor permite apoyar su significación. Vemos que con esta plantilla, hay un paso hacia el descubrimiento de la significación de una fotografía, permitiendo guiar al usuario en la reutilización de las mismas.

Además, se usaron las leyendas y palabras clave de las fotografías asignadas por los fotógrafos y documentalistas del IRD, para completar el análisis y para evitar errores de indización. Se analizaron los signos de la fotografía, desde arriba hacia abajo, para realizar un análisis completo de la misma. 
La duda que se puede plantear es la extensión de la descripción de una imagen. Bléry (1981) recomienda seguir un método riguroso que toma en consideración todo lo que ocurre en el documento: dónde, quién, cuándo y qué hacen las personas. Según un análisis de la normalización de los elementos de contenidos de las leyendas de 42 fotografías (Doucet, 2008c), se utilizan los elementos "quién" y "dónde", y en menor porcentaje "qué" y "cuándo", lo que corresponde a las facetas de Shatford (Shatford Layne, 1986) y a las recomendaciones de Bléry, aunque su uso no está normalizado. También debemos tener en cuenta que el análisis de una fotografía no es un fin en sí mismo, sino un medio para encontrar los documentos (Bléry, 1981). Lo que significa que según las necesidades de cada centro de documentación, fototeca o banco de imágenes la extensión de la descripción será variable. Cuanto más extensa sea la descripción, más entradas tendrá en la base de datos para poder ser recuperada.

\section{RESULTADOS Y FUNCIONALIDAD DE LA PLANTILLA}

Aplicamos este método con una plantilla (véase el anexo) a 42 fotografías del IRD y comprobamos su funcionalidad. Al ser una investigación cualitativa, se eligieron las 42 fotografías según el método no probabilístico, de tipo opinático, hasta llegar al principio de saturación. El tema de medio ambiente se eligió por ser un tema de actualidad, tratado desde un punto científico, periodístico o artístico. Se eligieron 21 fotografías del tema de los glaciares y 21 del tema de desertificación (Doucet, 2008a).

Presentamos los resultados centrándonos en los elementos morfológicos que ofrecen algún tipo de significado y en los elementos textuales (objetivo específico 2) antes de ver la funcionalidad de la plantilla (objetivo específico 3).

Se presenta a continuación el porcentaje de los elementos morfológicos que ofrecen algún significado. Se indican los porcentajes según el total de cada subtema y según el total del muestreo:

Tabla 1. Porcentaje de los elementos morfológicos con significados (Doucet, 2008a)

\begin{tabular}{|r|r|r|r|}
\hline \multicolumn{1}{|c|}{ Elementos } & Glaciares & Desertificación & \multicolumn{1}{c|}{ Total } \\
\hline Formato original & 100,00 & 100,00 & 100,00 \\
\hline Color & 100,00 & 100,00 & 100,00 \\
\hline Óptica & 85,71 & 85,71 & 85,71 \\
\hline Iluminación & 100,00 & 100,00 & 100,00 \\
\hline Encuadre & 100,00 & 100,00 & 100,00 \\
\hline Ángulo & 61,90 & 19,05 & 40,48 \\
\hline
\end{tabular}


Podemos concluir diciendo que la mayoría de los elementos formales tienen significados, es decir, transmiten alguna connotación. Solamente, el ángulo y la óptica no transmiten connotación, porque son ángulo y objetivos normales.

A continuación, vemos los porcentajes de los elementos textuales que incluyen algún elemento de Lasswell, según los tres niveles del modelo de Panofsky. Los porcentajes se indican según el total del subtema y luego según el total del muestreo:

Tabla 2. Porcentaje de los elementos textuales en los niveles de Panofsky (Doucet, 2008a)

\begin{tabular}{|c|l|r|r|r|}
\hline Niveles & Elementos de Lasswell & Glaciar & Desertificación & Total \\
\hline \multirow{4}{*}{ Pre-iconográfico } & Quién & 85,71 & 80,95 & 83,33 \\
\cline { 2 - 5 } & Qué & 33,33 & 9,52 & 21,43 \\
\cline { 2 - 5 } & Dónde & 28,57 & 0,00 & 14,29 \\
\cline { 2 - 5 } & Cuándo & 0,00 & 0,00 & 0,00 \\
\hline \multirow{4}{*}{ Iconográfico } & Quién & 95,24 & 66,67 & 80,95 \\
\cline { 2 - 5 } & Qué & 42,86 & 23,81 & 33,33 \\
\cline { 2 - 5 } & Dónde & 100,00 & 100,00 & 100,00 \\
\cline { 2 - 5 } & Cuándo & 100,00 & 100,00 & 100,00 \\
\hline & Quién & 90,48 & 100,00 & 95,24 \\
\cline { 2 - 5 } & Qué & 4,76 & 0,00 & 2,38 \\
\cline { 2 - 5 } & Dónde & 0,00 & 0,00 & 0,00 \\
\cline { 2 - 6 } & Cuándo & 0,00 & 0,00 & 0,00 \\
\hline
\end{tabular}

Los elementos textuales (leyenda y palabras clave) que acompañan las fotografías son importantes a la hora de identificar los componentes toponímicos y cronológicos. En el caso del nivel iconográfico, se han utilizado en el $100 \%$ de sus casos.

Queremos destacar que los elementos textuales permiten identificar el componente "quién", en la mayoría de los casos, tanto en el nivel pre-iconográfico como en el nivel iconológico.

Podemos concluir afirmando que estos elementos textuales son necesarios para agilizar el trabajo de identificación del contenido de las fotografías.

La siguiente tabla presenta los porcentajes de los elementos textuales de Lasswell que presentan connotaciones a nivel pre-iconográfico. Se presentan los porcentajes según el total de cada subtema y según el total del muestreo: 
Tabla 3. Porcentaje de los elementos de Lasswell con connotaciones en el nivel pre-iconográfico (Doucet, 2008a)

\begin{tabular}{|c|l|r|r|r|}
\hline Nivel & \multicolumn{1}{|c|}{ Elementos de Lasswell } & Glaciar & Desertificación & \multicolumn{1}{c|}{ Total } \\
\hline \multirow{3}{*}{$\begin{array}{c}\text { Pre- } \\
\text { iconográfico }\end{array}$} & Quién & 100,00 & 100,00 & 100,00 \\
\cline { 2 - 5 } & Qué & 23,81 & 4,76 & 14,29 \\
\cline { 2 - 5 } & Dónde & 38,10 & 71,43 & 54,76 \\
\cline { 2 - 6 } & Cuándo & 0,00 & 0,00 & 0,00 \\
\hline
\end{tabular}

Esta plantilla permite encontrar connotaciones a nivel de los signos, en todos los casos de los componentes representados por el "quién" y en la mitad de los casos de los elementos "dónde". Recordamos que esta connotación puede ser objetiva y subjetiva.

Se analizaron las connotaciones encontradas en el nivel iconológico y pertenecen en la mayoría de los casos al elemento "quién”. Los demás elementos de Lasswell no ofrecen signos.

La tabla siguiente presenta el porcentaje de los elementos de composición que ofrecen significados. Se ofrecen los porcentajes según el total de cada subtema y según el total del muestreo:

Tabla 4. Porcentaje de los elementos de composición con significados

\begin{tabular}{|r|r|r|r|}
\hline Elementos & Glaciar & Desertificación & Total \\
\hline Reglas tercios & 95,24 & 100 & 97,62 \\
\hline Líneas & 61,90 & 47,62 & 54,76 \\
\hline Colores & 66,67 & 61,90 & 64,28 \\
\hline Contraste signos & 42,86 & 38,09 & 40,48 \\
\hline
\end{tabular}

Los elementos que más significados ofrecen son la regla de los tercios, los colores, las líneas y, en menor proporción, el contraste entre los propios signos de la fotografía.

Para comprobar que esta plantilla permite encontrar pistas informativas, escribimos a los fotógrafos para conocer sus intenciones informativas. Se contestaron el $60 \%$ de los correos, lo que corresponde a 25 de las 42 fotografías seleccionadas. Comparamos nuestras pistas informativas con sus intenciones informativas y concluimos que se correspondían, lo cual significa que este método permite detectar pistas informativas.

Gracias a esta plantilla, tenemos todos los elementos para redactar el resumen de la fotografía. Proponemos la siguiente estructura del resumen, que refleja los diferentes campos de una base de datos: 
- Datos bibliográficos: nombre del fichero de la fotografía, nombre fotógrafo, su afiliación, título de la fotografía y leyenda, fecha de la toma fotográfica, firma del analista, fecha del análisis, tamaño de la fotografía, peso de la fotografía.

- Datos descriptivos: datos morfológicos, datos denotativos según los tres niveles de Panofsky.

- Palabras clave temáticas, onomásticas, toponímicas, cronológicas, connotativas, según los niveles de Panofsky.

- Pistas informativas posibles

- Fotografías relacionadas (por su fecha, su lugar, su tema...)

\section{CONCLUSIONES}

La plantilla propuesta permite descomponer las fases de análisis de las fotografías y obtener los datos para la redacción de su resumen así como para la asignación de unas palabras clave para su incorporación en una base de datos. Además, permite encontrar elementos de significación en las diferentes fases del análisis. En primer lugar, el análisis morfológico permite analizar cada elemento y conocer sus significados permitiendo utilizarlos como palabras clave connotativas. En segundo lugar, los modelos utilizados para el análisis de contenido permiten analizar las fotografías formalmente y destacar significaciones. Los modelos de Lasswell y de Panofsky analizan las fotografías de forma ordenada y estructurada: el modelo de Lasswell identifica los elementos semánticos presentes en ellas mientras que el modelo de Panofsky los jerarquiza según sus tres niveles, respondiendo a distintas necesidades de los usuarios. Además, la semiología destaca cada signo de la fotografía obteniendo su significación y su connotación, aumentando así las palabras clave connotativas $\mathrm{y}$, por consiguiente, las posibilidades de recuperación. En tercer lugar, el análisis de la composición completa el análisis morfológico y los descriptores connotativos. Por último, la detección del valor de los signos destacados en el análisis de contenido, permite distinguir la importancia que tienen entre ellos y así detectar pistas informativas. Por eso, podemos concluir afirmando que el análisis pormenorizado a través de esta plantilla ofrece los elementos imprescindibles para su posterior resumen y permite detectar pistas informativas.

Destacamos que la connotación existente en la fotografía científica puede encontrarse tanto en los elementos morfológicos y en la composición que reflejan la intención del fotógrafo, como en los propios signos de la fotografía.

Destacamos la importancia de la leyenda para encontrar los elementos que no se ven en la fotografía. Éstos son, y coincidimos con Enser (2007), el tiempo, el lugar, los eventos y el significado. Al ser elementos que sólo los sabe el fotógrafo, pensamos que es necesaria una interacción documentalista - fotógrafo para conseguir un análisis científico sin errores de indización. Se puede conseguir 
mediante la redacción sistematizada de una leyenda y algunas palabras clave por parte del fotógrafo, puesto que posee los conocimientos científicos necesarios para describir con sus palabras lo que ha visto de relevante para ilustrar su propósito científico. Otra idea de colaboración puede ser, como la menciona Ménard (2012), entre investigador y usuario.

\section{REFERENCIAS BIBLIOGRÁFICAS}

ACRL/IRIG (2011) Visual literacy competency Standard for higher education. Draft 02/09/2011

BARTHES, Roland (2002). Lo obvio y lo obtuso: imágenes, gestos, voces. Barcelona: Paidós.

- (1990). La aventura semiológica. Barcelona: Paidós.

- (1964). Eléments de sémiologie. Communications vol. 4, 91-135.

BERGER, John (2000). Modos de ver. Barcelona: Gustavo Gili.

BLERY, Ginette (1981). "La mémoire photographique: étude de la classification des images et analyse de leur contenu à l'aide de l'informatique". Analyse de l'image fixe: réflexions et guide bibliographique. Interphotothèque, vol. 41, 9-33. Paris: La Documentation Française.

- (1976). "La mémoire photographique: étude de la classification des images et analyse de leur contenu à l'aide de l'informatique." Director: Abraham Moles. Tesis Doctoral. Université Louis Pasteur.

CACALY, Serge (2005). La véritable rétine du savant ou l'IST racontée par l'image. Documentaliste - Sciences de l'Information, vol. 42, pp. 366-374.

CAHUZAC, Hubert (2000). L'analyse et le résumé documentaires de documents filmiques: fondements méthodologiques. Tesis Doctoral. Universidad de Burdeos III.

CHAUMIER, Jacques (1988). Le traitement linguistique de l'information. Paris: Entreprise Moderne d'Edition.

CHUNG, Eun Kyung; YOON, Jung Won (2011). Image need in the context of image use: an exploratory study. Journal of Information Science, vol. 37, $\mathrm{n}^{\mathrm{o}}$ 2, pp. 163-177.

DOUCET, Anne-Vinciane (2008a). "Análisis de contenido y propuesta de metadatos para la representación documental de la fotografía científica: un estudio de casos." Directora: María Pinto Molina. Tesis Doctoral. Universidad de Granada, Departamento de Biblioteconomía y Documentación. Disponible en http://hdl.handle.net/10481/1816 [Consulta: 25 de abril de 2013].

- (2008b). La descripción de las imágenes en Internet a través del análisis de 30 bancos de imágenes. Revista General de Información y Documentación, vol. 18, pp. 81-105.

- (2008c). El análisis de la normalización de los elementos de contenido de las leyendas y palabras clave de fotografías científicas. Acimed vol.18 (2). Disponible en http://www.bvs.sld.cu/revistas/aci/vol18_2_08/aci05808.pdf [Consulta: 18 de marzo de 2009] 
ENSER, Peter (2008). The evolution of visual information retrieval. Journal of Information Science, vol.34, nº , pp. 531-546.

ENSER, Peter, SANDOM, Christine J. (2007). Facing the reality of semantic image retrieval. Journal of Documentation, vol. 63, $\mathrm{n}^{\circ}$ 4, pp. 465-481. 2007.

FERNÁNDEZ DÍEZ, Federico; MARTÍNEZ ABADÍA, José (2001). Manual básico de lenguaje y narrativa audiovisual. Barcelona : Paidós.

GERVERAU, Laurent (1997). Voir, comprendre, analyser les images. Paris: Editions de la Découverte.

GUBERN, Román (1988). Mensajes icónicos en la cultura de masas. Barcelona: Lumen.

HERNÁNDEZ PÉREZ, Antonio (1992). Documentación audiovisual: metodología para el análisis documental de la información periodística audiovisual. Tesis Doctoral. Director: Antonio García Gutiérrez. Universidad Complutense de Madrid.

HOLLINK, L; SCHREIBER, A. TH.; WIELINGA, B. J.; WORRING, M. (2004). Classification of user image descriptions. International Journal of Human-Studies vol. $61, \mathrm{n}^{\circ} 5$, pp. 601-626.

HUDRISIER, Henri (1982). L'iconothèque: documentation audiovisuelle et banque d'images. Paris: La Documentation Française.

JAIMES, A.; CHANG, S-F. (2000). A conceptual framework for indexing visual information at multiple levels. IS\&T/SPIE Internet Imaging, 3964.

JOLY, Martine (1994). Introduction à l'analyse de l'image. Paris: Nathan.

KATTNIG, Cécile (2005). Gestion et diffusion d'un fonds d'images. Paris: Armand Colin.

KATTNIG, Cécile; LEVEILLE. Janny (1989). Une photothèque: mode d'emploi. Paris: Éditions d'Organisation.

LEE, Hyuk-Jin; NEAL, Diane (2010) A new model for semantic photograph description combining basic levels and user-assigned descriptors. Journal of Information Science, vol. 36, $\mathrm{n}^{\circ} 5$, pp. 547-565.

LISSALDE, Claire (2001). L'image scientifique: définitions, enjeux et questions. $B B F$, vol. $46,26-33$.

MADRID DÍAZ, María Victoria (1999). Análisis documental: fotografía de prensa. En García Gutiérrez, A.L. Introducción a la documentación informativa y periodística. Alcalá de Guadaira (Sevilla): MAD. P.305-331.

MASSIGNON, Valérie (2002). La recherche d'images: méthodes, sources et droits. Bruxelles: INA, De Boeck.

MELOT, Michel (2005). L'image n'est plus ce qu'elle était. Documentaliste Sciences de l'information, vol. 43, pp.138-139.

- (1994). L'image est-elle normalisable? Cahiers du Collège iconique, vol. 3, pp. 3-20.

MÉNARD, Elaine (2009). Traitement documentaire de l'image ordinaire. Analyse de deux approches d indexation. Documentation et Bibliothèques, vol. 55, $\mathrm{n}^{\circ} 1$, pp. 29-38.

MÉNARD, Elaine; SMITHGLASS, Margaret (2012) Digital image description: a review of best practices in cultural institutions. Library Hi Tech, vol. 30, $\mathrm{n}^{\circ}$ 2, pp. 291-309. 
MOREIRO, José Antonio (2001). Significantes y significados en el análisis documental de la imagen. En PINTO, María Catalogación de documentos: teoría y práctica. Madrid: Síntesis. Pp. 95-418.

PANOFSKY, Erwin (1998). El significado en las artes visuales. Madrid: Alianza Editorial.

- (1972). Estudios sobre iconología. Madrid: Alianza Editorial.

PÉQUIGNOT, Bruno (2006). De l'usage des images en sciences sociales. Communications vol. 80, 41-52.

PINTO, María; GARCÍA MARCO, Francisco Javier; AGUSTÍN LACRUZ, María del Carmen (2002). Indización y resumen de documentos digitales y multimedia: técnicas y procedimientos. Gijón: Trea.

PORCHER, Louis (1976). Introduction à une sémiotique des images: sur quelques exemples d'images publicitaires. Paris: Didier, Crédif.

POZZER-ARDENGHI, Lilian; WOLFF-MICHAEL, Roth (2005). Photographs in lectures: gestures as meaning-speaking resources. Linguistics and education, vol. 15 , pp. 275-293.

RASMUSSEN, Edie M. (1997). Indexing images. Annual Review of Information Science and Technology, vol. 32, pp. 169-196.

RITTAU, Andreas (2007). Le produit in situ: analyse (sémiotique) d'une photographie d'Andreas Gursky 99 cent. Semiotica, vol. 166, pp 97-104.

ROBLEDANO ARILLO, Jesús (2000). Documentación fotográfica en medios de comunicación social. En MOREIRO GONZÁLEZ, José Antonio; Caridad Sebastián, M. Manual de documentación informativa. Madrid: Cátedra. p. 183-290

SAUSSURE, Ferdinand de (1973). Cours de linguistique générale. Paris: Payot.

SHATFORD LAYNE, Sara (1986). Analyzing the subject of a picture: a theoretical approach. Cataloging \& Classification Quarterly vol. 6, n³ , pp. 39-62.

SICARD, M. (1993). Les images de la science ou "qu'est-ce que voir?" Cahiers Du Collège Iconique, vol.1, pp. 95-118.

STEPHENSON, Christie (1999). Recent developments in cultural heritage image databases : directions for user-centered design. Library Trends, vol. 48, pp. 410-437.

VALLE GASTAMINZA, Félix del. (1993). El Análisis documental de la fotografía. Cuadernos de Documentación Multimedia, $\mathrm{n} 4$.

VETTRAINO-SOULARD, Marie-Claude (1983). Lire une image: analyse de contenu iconique. Paris: Armand Colin.

WERTEL-FOURNIER, Isabelle (1999). "L'iconographe dans le labyrinthe des images et des mots: pour un imagier numérique dans l'espace cartografié de l'iconothèque." Tesis Doctoral. Villetaneuse, Paris VIII. 


\section{ANEXO}

Tabla 5. Análisis morfológico (Doucet, 2008a)

\begin{tabular}{|c|c|c|}
\hline ELEMENTOS & TIPOS DE ELEMENTOS & SIGNIFICADOS \\
\hline $\begin{array}{l}\text { FORMATO } \\
\text { DIGITAL }\end{array}$ & $\begin{array}{ll}- & \text { Jpg } \\
- & \text { Tamaño fichero } \\
- & \text { Tamaño imagen en píxeles } \\
\end{array}$ & \\
\hline $\begin{array}{l}\text { CALIDAD } \\
\text { TÉCNICAS }\end{array}$ & $\begin{array}{ll}\text { - } & \text { Proyección (buena, desaconsejada) } \\
\text { - } & \text { Impresión (buena, desaconsejada) } \\
\text { - } & \text { Ampliación (buena, desaconsejada) } \\
\end{array}$ & \\
\hline $\begin{array}{l}\text { FORMATO DEL } \\
\text { ORIGINAL }\end{array}$ & $\begin{array}{ll}- & \text { Rectangular } \\
\text { - } & \text { Cuadrado } \\
\text { - } & \text { Encuadre vertical u horizontal } \\
\end{array}$ & \\
\hline COLOR & $\begin{array}{ll}- & \mathrm{Si} \\
- & \mathrm{No} \\
\end{array}$ & \\
\hline $\begin{array}{l}\text { ÓPTICA } \\
\text { UTILIZADA }\end{array}$ & $\begin{array}{ll}- & \text { Teleobjetivo } \\
- & \text { Gran angular } \\
- & \text { Macro- o microfotografía } \\
- & \text { Endoscopia } \\
\text { - } & \text { Panorámica } \\
\text { - } & \text { Ojo de pez } \\
\text { - } & \text { Filtros (ayudas a la luz natural) }\end{array}$ & \\
\hline ILUMINACIÓN & $\begin{array}{ll}- & \text { Natural } \\
- & \text { Artificial } \\
- & \text { Día } \\
- & \text { Noche } \\
- & \text { Luz dura } \\
\text { - } & \text { Luz difusa } \\
\text { - } & \text { Contraluz } \\
\text { - } & \text { Luz lateral } \\
- & \text { Luz cenital } \\
- & \text { Luz enfática } \\
- & \text { Luz frontal } \\
\end{array}$ & \\
\hline $\begin{array}{l}\text { VALORES DE } \\
\text { ENCUADRE }\end{array}$ & $\begin{array}{ll}- & \text { Gran plano general } \\
\text { - } & \text { Plano general } \\
\text { - } & \text { Plano entero } \\
\text { - } & \text { Plano tres cuartos (plano americano) } \\
\text { - } & \text { Plano medio } \\
\text { - } & \text { Primer plano } \\
\text { - } & \text { Primerísimo primer plano } \\
\text { - } & \text { Plano detalle } \\
\end{array}$ & \\
\hline $\begin{array}{l}\text { ÁNGULO DE LA } \\
\text { TOMA }\end{array}$ & $\begin{array}{ll}\text { - } & \text { Ángulo picado } \\
\text { - } & \text { Ángulo contrapicado } \\
\text { - } & \text { Ángulo normal }\end{array}$ & \\
\hline
\end{tabular}




\begin{tabular}{|c|c|}
\hline $\begin{array}{l}\text { POSICIÓN DEL } \\
\text { OBJETO EN EL } \\
\text { ESPACIO }\end{array}$ & $\begin{array}{ll}- & \text { Vista de frente } \\
\text { - } & \text { Vista de espalda } \\
\text { - } & \text { Vista de perfil, tanto derecho como } \\
& \text { izquierdo } \\
\text { - } & \text { Vista de tres cuartos delantero o } \\
& \text { trasero, y derecho o izquierdo }\end{array}$ \\
\hline $\begin{array}{l}\text { ESTRUCTURA } \\
\text { FORMAL }\end{array}$ & $\begin{array}{ll}- & \text { Escena } \\
- & \text { Retrato } \\
- & \text { Paisaje } \\
- & \text { Paisaje interior } \\
- & \text { Bodegón } \\
\end{array}$ \\
\hline
\end{tabular}

Tabla 6. Análisis denotativo y connotativo (Doucet, 2008a)

\begin{tabular}{|c|c|c|c|c|c|}
\hline NIVELES & ELEMENTOS & $\begin{array}{c}\text { DENOTACIÓN } \\
\text { PLANO DE } \\
\text { EXPRESIÓN } \\
\text { (SIGNIFICANTE) }\end{array}$ & $\begin{array}{c}\text { DENOTACIÓN } \\
\text { PLANO DE } \\
\text { CONTENIDO } \\
\text { (SIGNIFICADO) }\end{array}$ & $\begin{array}{l}\text { CONNOTACIÓN } \\
\text { OBJETIVA }\end{array}$ & $\begin{array}{l}\text { CONNOTACIÓN } \\
\text { SUBJETIVA }\end{array}$ \\
\hline & Quién & & & & \\
\hline & Qué & & & & \\
\hline & Dónde & & & & \\
\hline & Cuándo & & & & \\
\hline \multirow{4}{*}{ ICONOGRÁFICO } & Quién & & & & \\
\hline & Qué & & & & \\
\hline & Dónde & & & & \\
\hline & Cuándo & & & & \\
\hline \multirow{4}{*}{ ICONOLÓGICO } & Quién & & & & \\
\hline & Qué & & & & \\
\hline & Dónde & & & & \\
\hline & Cuándo & & & & \\
\hline
\end{tabular}

Tabla 7. Análisis complementario de la connotación y del mensaje a partir de la composición (Doucet, 2008a)

Elementos de composición y sus significados respectivos:

\begin{tabular}{|c|c|}
\hline ELEMENTOS & SIGNIFICADOS \\
\hline & \\
\hline & \\
\hline
\end{tabular}

Por último, enumeramos el valor formal y/o conceptual de los signos. 